\title{
Primary lymphosarcoma of the lung
}

\author{
G. M. RE E S ${ }^{1}$ \\ Department of Surgery, Brompton Hospital, London S.W.3
}

\begin{abstract}
Rees, G. M. (1973). Thorax, 28, 429-432. Primary lymphosarcoma of the lung. All cases of primary lymphosarcoma of the lung seen at Brompton Hospital over the last 20 years are reviewed. Clinical features and the results of special investigations are discussed together with an analysis of the results of different forms of treatment.
\end{abstract}

Primary pulmonary lymphosarcoma-in contrast to secondary involvement of the lung in the generalized form-is extremely rare (Vieta and Craver, 1941 ; Willis, 1948 ; Robbins, 1953 ; Papaioannou and Watson, 1965). Sporadic reports have detailed the clinical features and the effect of therapy. The prognosis is said to be relatively good and long-term survival has been recorded with or even without treatment (Papaioannou and Watson, 1965 ; Jenkins and Salm, 1971). The total experience at Brompton Hospital over the last 20 years is reviewed.

\section{PATIENTS}

A diagnosis of primary lymphosarcoma of the lung was made in seven patients at this hospital in the last 20 years (Table I). Four were female and three were male. Their mean age was 48 (range 36-67) years.

Four cases presented with persistent chest pain while one was hoarse. Two were asymptomatic and had abnormal routine chest radiographs. Clinical exam-

T A B LE I

CLINICAL DETAILS

\begin{tabular}{|c|c|c|c|c|c|}
\hline Patient & Age & Sex & Symptoms & Signs & Site \\
\hline 1 & 36 & $\mathbf{F}$ & Nil & Nil & Left lower \\
\hline $\begin{array}{l}2 \\
3\end{array}$ & $\begin{array}{l}37 \\
43\end{array}$ & $\begin{array}{l}\mathbf{M} \\
\mathbf{M}\end{array}$ & $\begin{array}{c}\text { Nil } \\
\text { Anorexia, } \\
\text { weight loss }\end{array}$ & $\begin{array}{l}\mathrm{Nil} \\
\mathrm{Nil}\end{array}$ & $\begin{array}{l}\text { Right lung } \\
\text { Right middle } \\
\text { lobe }\end{array}$ \\
\hline 4 & 67 & $\mathbf{F}$ & $\begin{array}{l}\text { Dyspnoea, } \\
\text { chest }\end{array}$ & $\begin{array}{l}\text { Right } \\
\text { pleural } \\
\text { effusion }\end{array}$ & $\begin{array}{l}\text { Right upper } \\
\text { lobe }\end{array}$ \\
\hline 5 & 62 & $\mathbf{F}$ & $\begin{array}{l}\text { Lethargy, } \\
\text { chest pain }\end{array}$ & & $\begin{array}{l}\text { Left upper } \\
\text { lobe }\end{array}$ \\
\hline 6 & 56 & $\mathbf{F}$ & $\begin{array}{c}\text { Hoarse } \\
\text { voice, } \\
\text { chest } \\
\text { pain }\end{array}$ & $\begin{array}{r}\text { Vocal cord } \\
\text { paralysis }\end{array}$ & $\begin{array}{l}\text { Left upper } \\
\text { lobe }\end{array}$ \\
\hline 7 & 36 & $\mathbf{M}$ & Chest pain & Nil & $\begin{array}{l}\text { All lobes right } \\
\text { lung, left } \\
\text { lower lobe }\end{array}$ \\
\hline
\end{tabular}

Sputum cytology negative, bronchoscopy normal, and diagnosis made at thoracotomy in all cases

1 Present address : Department of Thoracic Surgery, St. Bartholomew's Hospital, London EC1 ination was normal in all but two, one of whom had a pleural effusion while the other had a vocal cord palsy. None had hepatosplenomegaly, peripheral lymph node enlargement or other evidence of generalized disease. None had finger clubbing.

Routine laboratory investigations were normal in all. Cytological examination of the sputum was repeatedly negative for neoplastic cells; bronchoscopy showed no abnormality in any patient.

On each occasion the diagnosis was established by lung biopsy at thoracotomy. In three patients the tumour affected the left lung only and in three others the right lung only; one had bilateral involvement.

T A B L E I I

TREATMENT AND RESULTS

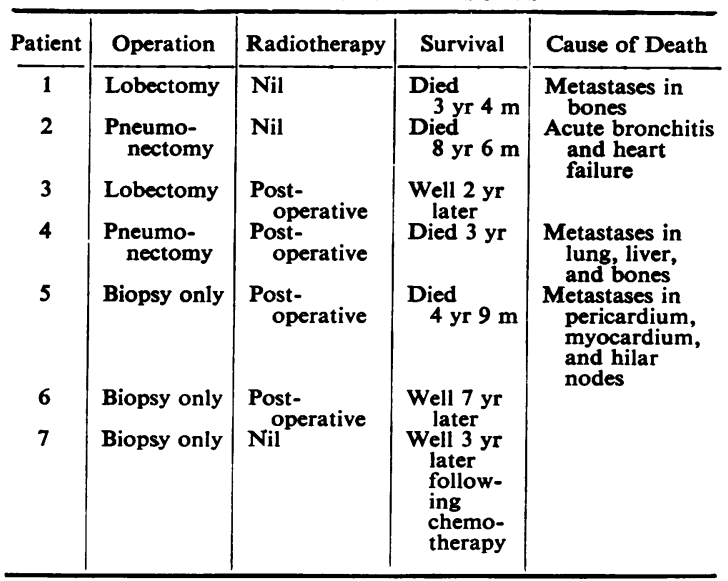

\section{TREATMENT AND RESULTS}

Resection was performed on four occasions (Table II).

In two patients lobectomy gave adequate macroscopic clearance while in two others pneumonectomy was required. Following resection in two 
of the four cases radiotherapy was given: patient 4 received 3,500 rads to the mediastinum ; patient 3 received 3,650 rads to the mediastinum, 3,840 rads to the supraclavicular nodes, and 3,890 rads to the axillae. Two patients were treated solely by radiotherapy. Patient 5 received 5,900 rads to the site of the tumour. No information is available concerning the dosage in patient 6 .

Owing to extensive bilateral intrapulmonary tumour involvement, patient 7 was treated by chemotherapy alone. Of the two treated by resection only, one died three years later of widespread metastases. The other (patient 2) showed unusual features. While under observation for chronic rheumatic heart disease he developed a persistent lung shadow (Fig. 1). This was found to be a pulmonary lymphosarcoma. Six years after pneumonectomy he had a partial gastrectomy for a haematemesis. The resected specimen revealed lymphosarcoma. One year later he developed peripheral neuropathy, thought to be of nonmetastatic origin. He died of acute bronchitis and heart failure the following year; no necropsy was carried out.

One of two patients treated by surgical excision and postoperative radiotherapy died of metastases

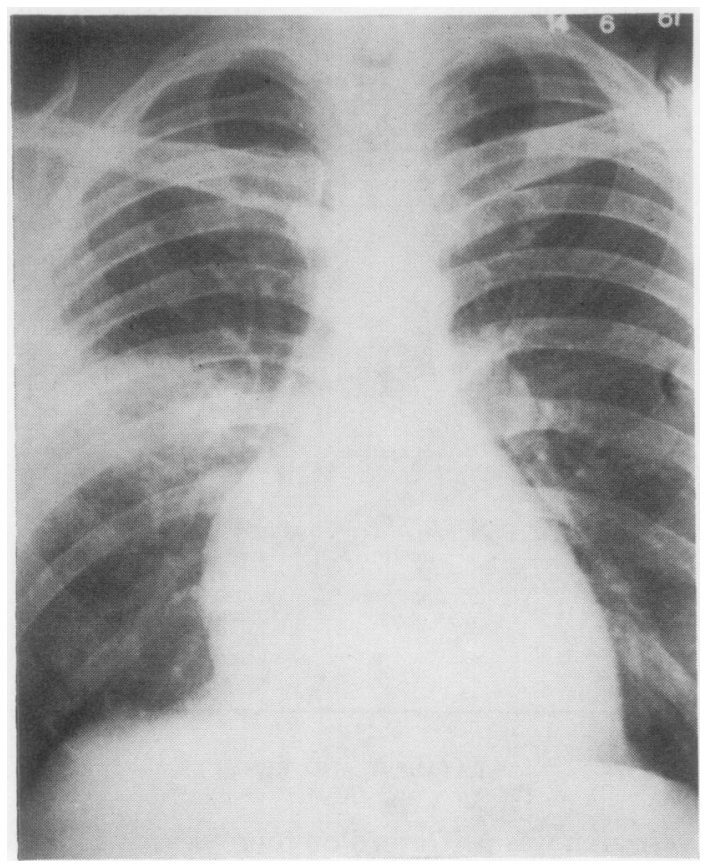

FIG. 1. Patient 2. A routine chest radiograph revealed an opacity in the right lung, which at thoracotomy proved to be a primary pulmonary lymphosarcoma. three years later; one is alive and well at two years.

Of two treated solely by radiotherapy, one died nearly five years later of metastases while one is alive at seven years.

The final patient with extensive pulmonary involvement was treated with chlorambucil initially in a dose of $12 \mathrm{mg}$ daily, with reduction over the next year. He is alive and well three years later.

Two patients who later developed evidence of generalized disease were then treated by chemotherapy. A combination of vincristine, cyclophosphamide, and prednisone in patient 1 gave a poor response ; as did a combination of rubidomycin, cytosine, and allopurinol.

Patient 5 was treated with vinblastine, chlorambucil, and prednisone but died of metastases.

\section{DISCUSSION}

Diagnostic criteria for primary lymphosarcoma of the lung are controversial (Papaioannou and Watson, 1965 ; Jenkins and Salm, 1971). There is little disagreement that generalized spread is incompatible with such a diagnosis, but uncertainty persists as to the extent of regional lymph node involvement compatible with the primary form. Papaioannou and Watson's (1965) view that hilar node involvement allows the diagnosis whereas mediastinal spread does not seem an arbitrarily harsh distinction. Equally, exclusion of those in whom the contralateral lung is involved is unrealistic when the tumour's properties of transgressing interlobar tissues and overlying pleura are well known. In addition, determination of the extent of spread is clearly dependent on the availability of diagnostic techniques: most cases reported here and also in the literature were diagnosed before the general use of lymphography. Further uncertainty occurs when intestinal involvement is discovered some years after the original diagnosis (patient 2). Evaluation of such cases has been attempted previously (Baron and Whitehouse, 1961; Saltzstein, 1963 ; Papaioannou and Watson, 1965).

The clinical features are often vague and results of routine investigations unrewarding. A persistent radiological pulmonary opacity in a middle-aged person of either sex (Fig. 1) may raise suspicions of primary lymphosarcoma: other possibilities include chronic paraffin pneumonitis or alveolarcell carcinoma of the lung. Finger clubbing is conspicuously absent (Jenkins and Salm, 1971). Nevertheless exploratory thoracotomy has almost 
always been necessary to establish the diagnosis (Rubin, 1968). It is likely, however, that the increasing use of percutaneous needle biopsy techniques may render open procedures unnecessary.

Although evidence of impaired peripheral nerve conduction may be present in approximately onethird of patients with generalized lymphosarcoma (Walsh, 1971), such changes in cases of primary pulmonary lymphosarcoma have not previously been reported.

The pathological properties of the tumour explain many of the clinical features. Infiltration of the lung occurs with little tissue destruction, and infiltration of the bronchi without mucosal involvement, while pressure on the bronchi is rarely seen. In addition, the tumour may spread across lobar fissures even to the contralateral lung.

Thus most cytological examinations of sputum show no abnormality (Papaioannou and Watson, 1965 ; Jenkins and Salm, 1971). Bronchial narrowing was not present in any of our patients, although it has been previously reported (Rubin, 1968). On the contrary, patent bronchi are frequently seen traversing opaque lung (Fig. 2),

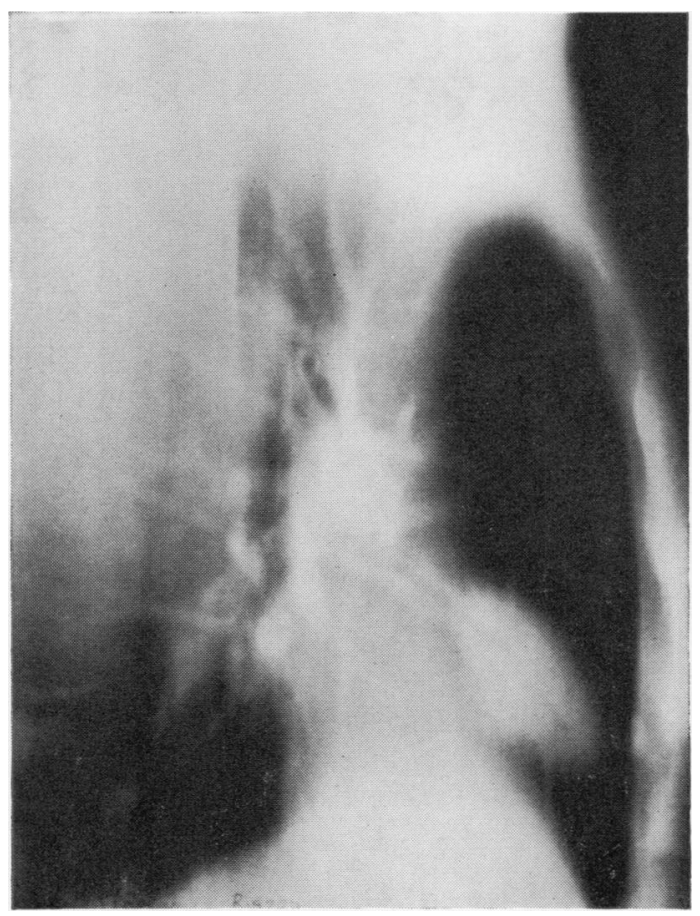

FIG. 2. Patient 3. Lateral tomogram showing consolidation of the middle lobe with a patent bronchus leading to it ('air bronchogram'). giving the appearance of an 'air bronchogram' (Baron and Whitehouse, 1961 ; Havard, Nichols, and Stansfeld, 1962 ; Jenkins and Salm, 1971).

Evaluation of different therapeutic approaches is hazardous in such a small group, but on the evidence available there does not appear to be any clearcut difference in the results obtained by surgery alone or by radiotherapy alone, while the addition of postoperative radiotherapy does not appear to add appreciably to long-term survival.

We used chemotherapy only in the treatment of advanced cases. In two patients the disease was widely disseminated and poor therapeutic response was obtained. The patient in whom both lungs were involved is alive and well three years later. Similar results in the management of primary pulmonary lymphomas have been achieved by Papaioannou and Watson (1965) with five-year survival rates of $44 \%$ following surgery alone, $42 \%$ after radiotherapy alone, and $40 \%$ after treatment with both. Indeed, long-term survival has occasionally been reported in the absence of therapy (Jenkins and Salm, 1971). Surgical resection is generally thought to be the most suitable form of treatment, particularly as the diagnosis is usually made at thoracotomy (Papaioannou and Watson, 1965). Some routinely add postoperative radiotherapy (Havard et al., 1962; Saltzstein, 1963) while others reserve it for poor operative risks or recurrence (Jenkins and Salm, 1971). It is apparent, however, that clinical experience is necessarily small and much uncertainty remains.

I am grateful to the physicians and surgeons of Brompton Hospital and the Royal Marsden Hospital for allowing me to publish the clinical details of their patients. I am also indebted to Dr. K. F. W. Hinson for advice on the histological aspects.

\section{REFERENCES}

Baron, M. G., and Whitehouse, W. M. (1961). Primary lymphosarcoma of the lung. American Journal of Roentgenology, 85, 294.

Havard, C. W. H., Nichols, J. B., and Stansfeld, A. G. (1962). Primary lymphosarcoma of the lung. Thorax, 17, 190.

Jenkins, B. A. G., and Salm, R. (1971). Primary lymphosarcoma of the lung. British Journal of Diseases of the Chest, 65, 225.

Papaioannou, A. N., and Watson, W. L. (1965). Primary lymphoma of the lung: an appraisal of its natural history and a comparison with other localized lymphomas. Journal of Thoracic and Cardiovascular Surgery, 49, 373. 
Robbins, L. L. (1953). The roentgenological appearance of parenchymal involvement of the lung by malignant lymphoma. Cancer, 6, 80.

Rubin, M. (1968). Primary lymphoma of lung. Journal of Thoracic and Cardiovascular Surgery, 56, 293.

Saltzstein, S. L. (1963). Pulmonary malignant lymphomas and pseudolymphomas: classification, therapy, and prognosis. Cancer, 16, 928.
Vieta, J. O., and Craver, L. F. (1941). Intrathoracic manifestations of the lymphomatoid diseases. Radiology, 37, 138.

Walsh, J. C. (1971). Neuropathy associated with lymphoma. Journal of Neurology, Neurosurgery and Psychiatry, 34, 42.

Willis, R. A. (1948). Pathology of Tumours, p. 766. Butterworths, London. 